\title{
The Prevalence of Depression among Medical Inpatients at the University Hospital of the West Indies, Jamaica
}

\author{
AN Morgan ${ }^{1}$, P Whitehorne-Smith ${ }^{2}$, A Coore $^{3}$, L Simms $^{3}$, WD Abel ${ }^{2}$, DT Gilbert ${ }^{1}$
}

\begin{abstract}
Objectives: The present research sought to determine the prevalence of depression and depressive symptoms among patients with chronic illness admitted to the medical ward at the University Hospital of the West Indies and the association between depression and sociodemographic characteristics among these patients.

Method: This was a cross-sectional study utilizing researcher administered questionnaires with the Brief Patient Health Questionnaire (PHQ-9) as the screening tool for depression. The study consisted of 76 participants and data were collected over a one-month period.

Results: The study revealed that one in three persons admitted to the medical ward during the period under study exhibited depressive symptomatology. However, no significant differences were noted between sociodemographic characteristics and the prevalence of depression.

Conclusion: The high prevalence of depression among patients with chronic illnesses admitted to the medical ward suggests need for greater attention to psychiatric evaluation in the care and treatment of these patients.
\end{abstract}

Keywords: Chronic illnesses, depression, medical ward

WIMJ Open 2015; 2 (1) 33

\section{INTRODUCTION}

Depression describes a group of disorders characterized by "persistent low mood, loss of interest and enjoyment in everyday activities, neurovegetative disturbance and reduced energy, causing varying levels of social and occupational dysfunction" (1). According to the World Health Organization (WHO), depression affects over 350 million people worldwide with a lifetime prevalence of 3-16.9\% (2). Wilks et $a l$, in their study, found that one in five Jamaicans were depressed, with $18 \%$ male and $25.6 \%$ female (3).

Depression is now the leading cause of disability worldwide and is more disabling than angina, arthritis, asthma and diabetes mellitus (2). It is the single most potent risk factor for suicide which claims more than one million lives annually (2). Depression is currently the leading cause of disease burden amongst women and the fourth leading cause of global disease burden; however, the WHO predicts that by 2030, it will be the leading cause, superseding ischaemic heart disease, road traffic accidents and cerebrovascular disease (2).

Depression often coexists with other medical problems whether as a predisposing factor or a sequel. In the United

From: ${ }^{1}$ Department of Medicine, ${ }^{2}$ Department of Community Health and Psychiatry, and ${ }^{3}$ Faculty of Medical Sciences, The University of the West Indies, Kingston 7, Jamaica, West Indies.

Correspondence: Professor W Abel, Department of Community Health and Psychiatry, The University of the West Indies, Kingston 7, Jamaica, West Indies. E-mail: drwendelabel@gmail.com
States of America, prevalence rates vary, from $20 \%$ in persons diagnosed with coronary artery disease to $25 \%$ amongst cancer, diabetic and stroke patients, to as high as $65 \%$ in patients who suffered a heart attack (4). This co-morbid depression is associated with decrements in quality of life, reduced social and physical functioning and increased mortality. There is also a significant increase $(>50 \%)$ in the use of medical services and costs, following more readmissions and longer duration of stay in hospital $(4,5)$.

Hutchinson et al found a depression prevalence rate of $28.3 \%$ in patients attending chronic disease clinics in southwest Trinidad and 40\% amongst the acutely medically ill patients requiring admission (6). In patients attending an HIV/AIDS outpatient clinic in Kingston, Jamaica, Clarke et al found a $43 \%$ prevalence of depression among HIV clinic attendees (7).

The presence of a chronic medical illness may reduce the likelihood of healthcare personnel recognizing and/or treating depression, as symptoms may be overlooked, be attributed to the co-morbid illness, or the question could be asked, "Who would not be depressed if they were diagnosed with cancer?" (8).

As a result of these observations, this study sought to look at depression in a clinical setting. The study explored the prevalence of depression amongst patients being admitted to the medical ward at the University Hospital of the West Indies (UHWI) as well as the associations between depression, diagnosis and sociodemographic details. 


\section{SUBJECTS AND METHOD}

This was a cross-sectional study which utilized a survey design. It consisted of male and female patients who were first-time admissions to the medical ward of the UHWI. Patients who were critically ill, unable to comprehend or offer proper responses, and those with a history of psychiatric disorders were excluded from the study.

This study utilized a researcher administered questionnaire to collect data. It consisted of baseline demographic questions along with the Brief Patient Health Questionnaire (PHQ-9). The PHQ-9 is very user friendly and based directly on the nine diagnostic criteria for major depressive disorder described in the Diagnostic and Statistical Manual of Mental Disorders, fourth edition (DSM-IV). It is used to screen for depression, classifying the patients into no, minimal, mild, moderate or severe depression.

The data collection team consisted of medical residents and medical students with some experience with diagnostic interviewing. The data collection team would visit the medical ward and perform a review of the dockets and conduct a brief interview with the admitted patients to see if they met the inclusion criteria. Once patients were willing to participate and signed the informed consent form, the questionnaire was administered. The data were collected over a one-month period. Once questionnaires were collected, they were placed in an envelope and stored for data entry.

Data were analysed using the Statistical Package for the Social Sciences (SPSS) version 12. Statistical significance was taken at the level $p<0.05$. Descriptive analyses and Chi-squared tests were performed on the data.

\section{RESULTS}

There were 116 new documented medical admissions over the data collection period. The study does not account for 40 patients who fulfilled the exclusion criteria, died or were discharged prior to being interviewed. The study included 76 eligible candidates: $58 \%$ female $(n=44)$ and $42 \%$ male $(n=$ 32).

The ages of the participants in the study ranged from 15 to above 75 years with the largest population being between 40 and 75 years old. A significant number of patients were from Kingston and St Andrew (35.5\%), followed by St Catherine (21.1\%). However, nearly all parishes were represented (except Trelawny and Hanover).

In terms of employment status, a significant number of participants reported being employed (47\%), 28\% were unemployed and 25\% were retired. Most persons had achieved up to a secondary level education (55.3\%) and only one person had received no formal education $(1.3 \%)$.

The most common marital status among respondents was single $(46.1 \%)$, followed by married $(26.3 \%)$ and common-law relationship $(10.5 \%)$. Additionally, the majority of the participants were members of a religious organization $(89 \%)$.

\section{Disease category}

The most common disease category of patients admitted to the ward was heart-related problems $(39.5 \%)$ with slightly more females $(40.9 \%)$ than males $(37.5 \%)$ reporting these illnesses. This was followed by nervous system problems $(10.5 \%)$. All other disease categories were reported in lower frequencies.

\section{Prevalence of depression}

Findings from the responses on the PHQ-9 revealed that $60.5 \%$ of respondents fell along the depression spectrum with $11.8 \%$ of patients being considered as having moderatesevere depression (Table 1).

Table 1: Depression status of participants

\begin{tabular}{lc}
\hline Depression status & Per cent \\
\hline No depression & 39.5 \\
Minimal symptoms & 23.7 \\
Mild major depressive disorder & 25.0 \\
Moderate - severe major depressive disorder & 11.8 \\
\hline
\end{tabular}

Additionally, more females $(60.5 \%)$ than males (53.1\%) exhibited signs of depression. However, this difference was not statistically significant $(p>0.05)$. It is important to note that the majority of both genders experienced some degree of depressive symptomatology (Table 2).

Table 2: Depression status of participants by gender

\begin{tabular}{lrrrrc}
\hline Depression status & \multicolumn{2}{c}{ Male } & \multicolumn{2}{c}{ Female } & \multirow{2}{*}{ Total (\%) } \\
& $\boldsymbol{f}$ & $\boldsymbol{\%}$ & \multicolumn{1}{c}{$\boldsymbol{f}$} & $\boldsymbol{\%}$ & \\
\hline No depression & 15 & 46.9 & 15 & 34.1 & 39.5 \\
Minimal depression & 6 & 18.8 & 12 & 27.3 & 23.7 \\
Mild major depression & 6 & 18.8 & 13 & 29.5 & 25.0 \\
Moderate major depression & 4 & 12.5 & 4 & 9.1 & 10.5 \\
Severe major depression & 1 & 3.1 & 0 & 0 & 1.3 \\
\hline Total & $\mathbf{3 2}$ & $\mathbf{1 0 0}$ & $\mathbf{4 4}$ & $\mathbf{1 0 0}$ & $\mathbf{1 0 0}$ \\
\hline
\end{tabular}

The results further revealed that one of every three admissions to the medical inpatient service has significant depressive symptoms and would benefit from psychiatric intervention.

There were no statistically significant differences between depression and age, educational level, employment status, marital status or type of diagnosis $(p>0.05$ in all cases).

\section{DISCUSSION}

Findings from this study revealed that the majority of the respondents expressed some amount of depressive symptomatology, ranging from minimal to severe $(60.5 \%)$. The study also revealed that approximately one in three persons on the medical ward reported depressive symptoms. This prevalence is higher than that found by Wilks et al which 
reported that an estimate of one in five Jamaicans in the general population experience depressive symptoms (3). Researchers have found a dynamic bidirectional relationship between depression and chronic illness where having a chronic illness can result in the development of depressive symptoms as well as having depressive symptoms can lead to the development of chronic illnesses (9). This supports findings that there is a high rate of co-morbidity between chronic illness and depression (9).

The study findings further revealed that slightly more females than males were experiencing depressive symptoms, but this finding was not statistically significant. This finding supported previous research by Novy et al in which there was no significant gender difference noted among patients with chronic medical illnesses (10).

There were no statistically significant differences found between depression and the sociodemographic characteristics of age, education level, employment status, marital status or type of diagnosis. Some researchers have found that simply having a chronic illness can trigger depression and that risk of depression increases based on the severity of the illness and how much disruption it causes to daily life $(9,11)$.

The primary limitation of this study is the sample size and the duration of time during which the data were collected. Consequently, these findings should be considered as preliminary results and they are not generalizable.

Also, this study could not comment much on depression in the elderly. Their lack of representation may be due to the fact that elderly patients were more likely to be critically ill, suffer from dementia etc and therefore fulfil the exclusion criteria; a geriatric depression tool could be considered.

\section{CONCLUSION}

Depression is a pervasive mental disorder and the available treatment options are efficacious and cost-effective (2). Preliminary as these findings may be, they provide useful data which have implications for future research. The inpatient setting provides a perfect opportunity for mental health screening and/or formal psychiatric evaluation given the limited access to mental health services locally. The prevalence of depression among this sample suggests the need for physician/healthcare professionals to look beyond the presenting diagnosis on the wards and be more aggressive toward diagnosing and treating co-morbid depression. This is one way to reduce morbidity, mortality and health expenses.

\section{REFERENCES}

1. BMJ Best Practice. Overview of depression [Internet]. BMJ Publishing Group Limited [cited 2013 Jul 24]. Available from: http://bestpractice. bmj.com/best-practice/monograph/1083.html

2. World Health Organization. Depression fact sheet no. 369 [Internet]. Geneva: WHO; 2012 [rev 2012 Oct; cited 2013 Jul 24]. Available from: http://www.who.int/mediacentre/factsheets/fs369/en/index.html

3. Wilks R, Younger N, Tulloch-Reid M, McFarlane S, Francis D. Jamaica Health and Lifestyle Survey 2007-8: technical report. Kingston: Epidemiology Research Unit, Tropical Medicine Research Institute, The University of the West Indies; 2008 [cited 2013 Jul 24). Available from: http://www.mona.uwi.edu/reports/health/JHLSII final_may09.pdf

4. Simon GE, VonKorff M, Barlow W. Health care costs of primary care patients with recognized depression. Arch Gen Psychiatry 1995; 52: $850-6$.

5. Frasure-Smith N, Lesperance F, Talajic M. Depression following myocardial infarction: impact on 6-month survival. JAMA 1993; 270: 1819-25.

6. Hutchinson G, Kodali S, Bruce C, Thomas C. Depressive symptoms among acute medical admissions to a general hospital. West Indian Med J 2003; 52 (Suppl 3): 51

7. Clarke TR, Gibson RC, Barrow G, Abel WD, Barton EN. Depression among persons attending a HIV/AIDS outpatient clinic in Kingston, Jamaica. West Indian Med J 2010; 59: 369-73.

8. Shah A, Jenkins R. Mental health economic studies from developing countries reviewed in the context of those from developed countries. Acta Psychiatr Scand 2000; 101: 87-103.

9. WJ Katon. Epidemiology and treatment of depression in patients with chronic medical illness. Dialogues Clin Neurosci 2011; 13: 7-23.

10. Novy DM, Nelson DV, Averill PM, Berry LA. Gender differences in the expression of depressive symptoms among chronic pain patients. Clin J Pain 1996; 12: 23-9.

11. National Collaborating Centre for Mental Health. Depression in adults with a chronic physical health problem; Royal College of Psychiatrists and the British Psychological Society; 2010 [cited 2014 Jun 18]. Available from: http://www.rcpsych.ac.uk/files/samplechapter/NICE depressionCPHP-SC.pdf

Submitted 13 Oct 2014

Accepted 27 Oct 2014

Published 16 Mar 2015

Online: http://www.mona.uwi.edu/wimjopen/article/1621

(C) Morgan et al 2015

This is an open access article made freely available under Creative Commons Attribution 4.0 International (CC BY 4.0). Users are free to share, copy and adapt this work as long as the copyright holder (author) is appropriately and correctly credited. See http:// creativecommons.org/licences/by/4.0/deed.en_us for more information. 